\title{
A Strategic Competitive Advantage Perspective on Management Development
}

\author{
Law Kian Aun \\ School of Graduate Studies, UCSI \\ E-mail:kalaw@ucsi.edu.my
}

\begin{abstract}
This paper attempts to evaluate relevant literature related to management development, competitive advantage as well as the links between management development and competitive advantage. This will be done through assessing the emerging role of management development in organizations, the dynamics of competitive advantage and conceptual model on linkage between management development and competitive advantage. The focus is on the link between management development and competitive advantage by comparing and contrasting two representative models through cross referencing and to suggest a conceptual model that fundamentally integrates both models. The findings of this review indicate that there are several aspects of the management development and competitive advantage models which are mutually inclusive especially in the areas of corporate vision and strategy, learning and knowledge as well as skills. Other integrated areas which were observed, are decision making, behavioural and cognition development. The proposed conceptual model suggests a methodological guideline and recommendation for implementation and practice of management development.
\end{abstract}

Keywords: Competitive advantage, Management development, Cross-referencing

\section{Introduction}

Management development (MD) and competitive advantage (CA) are fields that have been researched by personnel in academia and in industry. Despite the considerable research in both fields, there has been surprisingly, little done to show the links between the two fields. Luoma (2000) argued that the relationship has received amazingly scant attention whilst McClelland (1994) asserted that many organizations do not consider management development to be linked to their corporate competitiveness. Recent changes in the global competitive environment, for example, the formation of Asia Pacific Economic Cooperation (APEC) in 1989 and ASEAN Free Trade Area (AFTA) in 1992 has forced corporations, from small to big scale across industry types, to rethink their competitive strategies. As a result, organizations needed to build their competitive edge through MD activities in order to retain talented, experienced and adaptable managerial personnel. This is because capable management is perceived as one of the organizational resources to build corporate competitiveness. MD assumed an important role in realigning the organizations internal resources and functions for organizational success (Atkinson \& Meagher, 1986; Schuler, 1989). Millett and Leppanen (1991) further argued that MD's basic function is to help organizations to ensure that competent and knowledgeable managers are able to implement successfully the corporate strategies in facing anticipated business challenges.

Likewise, McClelland (1994) suggested that MD needs to be realigned with competitive strategy in order to ensure the availability of skills for effective strategic implementation.

It is meaningful to attempt to discover how MD is associated with the strategic competitiveness of organizations. In this context, Hussey (1985) agreed that MD should be integrated with organizational strategies and objectives. Berry (1990) further linked MD to business strategies by suggesting that skilful and capable managers assist in better decision making and strategy implementation. Moreover, Mann (1990) pointed out that MD enhances organizational competitive advantage by defending and progressing an organization's market position in the competitive market place. However, very little has been discussed about the practical methodological links between MD and CA (McClelland, 1994). Identification of this literature gap drives the purpose and aim of this study.

The main objective of this study is to establish if MD and CA could be linked in a conceptual framework and translated into a practical methodology to serve as a pedagogical guideline to improve organizational performance. In attempting to address the answer, this paper will conduct an assessment and evaluation of MD and CA and their possible linkages using a proposed conceptual framework by comparing the existing MD and CA models.

The findings of this study ought to shed light on organizations that practice MD, to recommend ways to broaden and improve organizational horizons and avoid misconceptions about practicing MD. The framework constructed in this 
paper serves as practical means to understand the potential of MD in relation to CA.

\section{Literature Review}

In evaluating the emerging role of MD in organizations, it is appropriate to define the concept of MD before proceeding to examine its emerging role in organizations. Lees (1992) conceptualised MD as the intersection of three variables, namely, the individual career, organizational succession and organizational performance. He reaffirms that the intersection of these three variables represents an entire system of corporate activities with the espoused goal of improving performance in the context of consistent environmental and organizational changes. Hence, MD is seen as a whole complex process by which individuals in the organizations learn, grow and improve their abilities to perform tasks related to management in organizational development activities. For example, performance appraisal, job rotation, career planning, and participation in teamwork are some organizational development activities.

Dikken and Hoeksema (2001) defined five major aspects of MD. They are (1) opportunity of learning at job; (2) controlling and managing learning process of managers; (3) learning on the job for career success; (4) conscious use of developmental instruments to influence managers' behaviour; (5) recommendation for managers and organizations to improve organizational performance and bottom-line results.

Likewise, Storey (1989a, 1989b) argued that MD represents an organizational process that enhances the capability of managers while leaving scope for creativity and interdependency. Jansen, van der Velve and Mul (2001) classified MD into four types which are (1) administrative MD which emphasizes lifetime employment for managers, including promotional opportunity based on the length of service and age; (2) dependent MD, which is dependent on organizational chosen strategy; (3) leading MD which concentrates on prior adequate selection than on latter training and development; and (4) partnership MD, which stresses filling key positions within an organization. These four types of MD suggest the importance of context in trying to understand the different definitions of MD. Thus, MD is perceived as the system of manpower practices by which an organization tries to place the right candidates at the right place at the right time.

Similarly, Taylor and Gordon (1984) claimed that MD is a part of a well coordinated organizational developmental programme which should be interlinked with corporate policies and strategies. They emphasized that it is imperative to develop managers for strategic thinking in the wake of organizational development and this is in line with current developments in the field of management development studies.

Similarly, Torrington and Hall (1998) suggested that MD is a system that focuses on developing the future roles of managers rather than what they are currently doing. Different definitions are used to describe MD. McClelland (1994) defined MD as one of the key organizational processes aimed at delivering successful organizational adaptation and renewal while Hitt (1987) refered to MD as a unified process that is coherent and integrates the organization's philosophy, mission, vision, business goals and human resource strategy across all functions and hierarchies.

Mumford (1993) set forth a more comprehensive definition of MD. He contends that MD can be categorised into three approaches, namely, the informal accidental process which should include the activities of informal and unconscious learning; the integrated managerial opportunistic process that encompass planned learning experiences and the formalised development planned process that focuses on structured learning activities. These approaches could be seen as a holistic ever-changing perspective of organization.

In understanding the stages of MD in an organization, Burgoyne (1988) identified six levels of maturity of MD progression within an organization. Level one represents no systematic practice of MD, level two shows an isolated and tactical style of MD, level three conclude with integrated and coordinated structured MD, level four sees MD strategy input to corporate policy, whereas level five conceives MD strategy input to the formation of corporate policy and eventually level six captures the strategic development of the management of the organization. These six levels of maturity of MD include both the structural and conceptual dimensions that are closely intertwined within an organizational design that provides an MD process.

Furthermore, Doyle (1994) suggested a system approach of studying of MD through an integral part of a wider organizational system that is linked to the context and reality of managerial work. He noted that MD is an open system that consists of the interplay of interrelated elements that directed towards common goals. Likewise, Morgan (1986) revealed that a system approach of MD exhibits the synthesising, integrative and relational qualities of an organization with its internal and external environment. It also fosters the awareness and pattern of causal relationship among the elements and their complex interactions. Such a perspective implies that MD as an open system is both a system and process that interacts with other organizational and environmental subsystems and activities.

In understanding MD from the investment rationale perspective, Lees (1992) suggested that there are ten rationales for investing in MD. According to him, MD is driven by these rationales that aim to improve managerial functioning and the overall corporate performance. The rationales are (1) functional performance, which aims to directly improve managerial functioning and corporate performance; (2) agricultural development, which focuses on the perceived needs 
of organizations to cultivate and develop managers internally; (3) functional defensive, where MD is perceived as an element of the core organizational strategic and management control process; (4) socialization, where MD is seen as a socialization of managers to share a common corporate value system; (5) political reinforcement, where MD acts as a political tool to reinforce the belief of controlling managers; (6) organizational inheritance, where MD is perceived as a crucial factor in corporate succession planning and career development; (7) environmental legitimacy, which advocates the rationale of internalizing the organizational legitimacy by conforming to environmental reality and its constituencies; (8) compensation, which advocates that MD should offer compensation at work to prevent employee alienation; (9) psychic defence, where MD serves as a social system against work anxiety; and (10) ceremonial, where MD is viewed as a ceremony designed to legitimise the social progression of managers. Quinn (1988) shared a similar view and further suggests that MD rationales represent a system of competing values in the organizations, both meant for the purpose of MD itself and the overall organizational objectives.

In other words, the differences in the definition of MD tend to occur between various researchers as a result of their different approaches towards the study of MD. For instance, the traditional definition tends to focus on the deliberate aspects of MD, which emphasizes the structured, planned and formal side of MD whereas the contemporary perspectives see MD as generic, which constitutes both formal and informal aspects of MD. In the systems approach of MD, emphasis is placed on seeing MD as neither fragmented nor piecemeal, but an integrated approach towards organizational competitiveness.

It follows therefore that the understanding of the need and emerging role for MD practices in the corporate sector is crucial especially under growing and intensified globalized competition. The Asia Pacific region, especially South East Asia, has been forecasted to achieve high rates of economic growth for the next decade (Asean Economic Bulletin, 1991), thus it is in this economically promising scenario that the future role of MD in building and sustaining organizational competitiveness lie.

There are other sources of MD literature which have extensively focused on selection, analysis of MD needs, managerial competencies, choice of delivery methods and evaluation of MD. A review of the literature is given below.

Sisson and Storey (1993) observed that success of managerial work is a function of possession of social skills and the individual personal qualities; hence, attention should be focused on selection in order to ensure the appropriate filling of managerial positions.

Doyle (1994) noted that effective MD requires systematic needs assessment based on the holistic approach. Mumford (1993) further described that performance appraisal is an effective mechanism to identify the skills and knowledge required for organizational performance. This means that systematic needs analysis is perceived as a fundamental procedure that should be realigned with the agreed management development plan, which, in turn, should be periodically reviewed and adapted to situational contexts.

Storey (1989a, 1989b) suggested that the competency-based approach to MD plays a major role in any successful MD initiative. Jones and Woodcock (1985) identified the competencies needed. They include the traditional categories of knowledge, skills, attitude and behaviour. Boyatzis (1982) shared a similar view and defined competency as the underlying qualities of a manager that ensures job success and performance. This emphasis on the emerging role of competency-based approach is in line with the current development in the field of MD (Jansen \& van der Velve, 2001; Paauwe \& Williams, 2001; Taylor \& Gordon, 1984;).

The literature of MD is further discerned in the choice of delivery and evaluation tenets. According to Mumford (1993), the integrated approach to on-the-job development has been successfully seen as a delivery method that places emphasis on both task performance and developmental opportunity.

On the other hand, Beddowes (1994) concluded that the emphasis on the MD evaluation is a result of clarity of organizational objective reflected through the MD design. However, Easterby (1994) cautioned that it is difficult to make causal relations between investment in MD and organizational performance. Constable and McCormick (1987) shared the same view and warned that it is difficult to establish a statistical link between MD and organizational performance.

All of the above definitions suggest that there is a possibe link between MD and competitiveness in organizations. The concept of MD is a practical approach to organizational improvement and performance. Mumford (1993) stressed on the systemic perspective which involves a continuous or unplanned and informal process of learning. This echoes Dikken and Hoeksema (2001) five aspects of MD which are significant to the understanding of the MD concept in this study. The five aspects are (1) opportunity of learning at job; (2) controlling and managing learning process of managers; (3) learning on the job for career success; (4) conscious use of developmental instruments to influence managers' behaviour; and (5) recommendation for managers and organizations to improve organizational performance and bottom-line results.

It is also helpful to understand the concept of CA with regard to its definitions and impact on organizational 
effectiveness. Different definitions are used to describe CA. Generally, there are two perspectives and views in defining CA, namely the outside-in perspective and the inside-out perspective. A leading outside-in theorist, Porter (1985) argued that as a firm's efficiency of strategic business unit (SBU) is mainly determined by industry attractiveness based on the five forces model, which is represented by (1) the rivalry among the competing firms; (2) bargaining power of suppliers; (3) bargaining power of consumers; (4) threat from potential entrants; and (5) threat from potential substitutes. As a result, the competitive position of SBU or its positional advantage can be achieved through cost and differentiation position. As a result, CA will be built for organizational success and performance. According to Porter (1985), firms should continuously adapt to the external environment when determining their strategies. Such a positioning approach ensures the market position for sustained profitability. In other words, insight into markets and industries is crucial as the general structure of markets and industries including the specific demands, strengths, positions and intentions of all five forces will be determined in response to external structural changes. However, Porter (1985) readily acknowledged the importance of firm resources as market opportunities will only be seized with the availability of such resources in order to ensure the implementation of the best market strategy.

By looking from the inside-out perspective, Foss (1996) shared a similar view but described CA in a different way. He defined CA as the art of accumulating and deploying organizational resources as opposed to Porter's definition which stressed the positional advantage derived from the analysis of industry structure. Castanias and Helfat (1991) echoed Foss's definition by saying that CA is derived from company resources owned by organizations.

Day and Wensley (1988) futher elaborated that organizations achieve positional advantage through investment in company assets and managerial capabilities. They contend that investment will result in a CA by leveraging sources which are valued by the customer through differentiation strategy. This concept of CA is uniquely identified from a capability-based perspective. It implies that learning skills which emphasize service quality, cost control, innovation and business speed will eventually form a competitive business position (Hamel \& Prahalad, 1994).

It is noted that although capability or learning skill is considered a source of organizational competency, the focus of CA has recently been diverted to resource-based view (RBV) or inside-out perspective (Smith, Vasudevan \& Tanniru, 1996). RBV emphasizes the critical importance of organizational internal resources for sustaining CA as opposed to the belief of positional advantage. In this regard, many researchers argue that organizational performance or the creation of CA is dependent on how well the companies resources that are rare (Barney, 1991), immobility (Peteraf, 1993), inimitability (Dierickx \& Cool, 1989; Godfrey \& Hill, 1995; Lippman \& Rumelt, 1982; Reed \& DeFillippi, 1990; Rumelt, 1984; ), valuable and lack of possibility of substitute (Rumelt, 1984; Teece, Pisano \& Shuen, 1997). CA is also dependent on social complexity (Barney, 1991; Dierickx \& Cool, 1989; King \& Zeithaml, 2001), causal ambiguity (Arthur, 1996; Badaracco, 1991; King \& Zeithaml, 2001; Lippman \& Rumelt, 1982; Mosakowski, 1997) and skills and knowledge (Polanyi, 1967; Reed \& DeFillippi, 1990) that are built by managers. They contend that the more the advantages of these characteristics, the better the sustainability of CA through the interaction and intermediation of organizational competency.

In identifying factors that lead to measuring $\mathrm{CA}$, some researchers tend to express concern over the elusive concept of CA from the RBV perspective. Smith, Vasadevan and Tanniru (1996) alleged that building a CA is time consuming, RBV's static perspective has over focused on the result rather than on the process of constructing CA. As a result, the potential contribution of RBV to CA is limited and ignored as measuring CA based on a point of time is less dynamic and non realistic to reflect the actual strength of organizational CA.

Empirical evidence suggests that strong and sustainable CA has a positive influence on organizational effectiveness (McClelland, 1994). A sustainable CA promotes organizational performance and the outcome is high productivity in terms of better resource allocation and utilization. It thus suggests that a sustainable CA does have a positive impact on overall organizational performance. However, a sustainable CA could be considered effective if it manages to assist in achieving organizational goals and objectives.

Given that the objectives of both MD and CA are organizational efficiency and effectiveness, it seems logical for MD to be perceived as a strategic resource in helping organizations to achieve the goals and objectives.

However, current literature fails to link both fields in an integrated conceptual model. McClelland (1994) argued that MD has assumed a more important role in the internal alignment of resources and functions. Millett and Leppanen (1991) further claimed that MD ensures that organizations have identified and mobilized the capable managers in implementing the corporate strategy. Likewise, Hussey (1985) and McCall (1992) asserted that MD should be closely integrated with organizational objectives and strategies.

Furthermore, Mann (1990) found that organizations have instituted MD to enhance their CA in order to maintain and progress their market position in the industries. Consistent monitoring of MD activities thus is needed to ensure better managerial performance and effiency as a result of improved CA. Yet, very little has been done to integrate and link the two concepts (Luoma, 2000; McClelland, 1994). 
It is noted that there remains a gap in the link between MD and CA despite the above arguments. While the literature is helpful in emphasising aspects of MD and CA, what seems to be lacking is the conceptual framework linking the two areas of study in terms of organizational transformation (action approach) and not only on organizational description (narrative approach). Thus, a conceptual model is developed to explore the

links and also to simplify the theme (the strategic role of MD) that is identified in the literature.

\section{Discussion: Links between Management Development and Competitive Advantage}

\subsection{Conceptual framework}

Much of the literature focuses on the strategic role of MD in situational context, for instance, Catalanello and Redding (1989) stated that the strategic role of management developmental function should be emphazised by organizations. Torraco and Swanson (1995) discussed the importance of MD in supporting and shaping corporate strategies.

On the other hand, Mabey and Salaman (1995) viewed the relationship between MD and strategy as a means to assess and identify skill deficiencies in organizations. In this regard, Pettigrew, Henry and Sparrow (1988) pointed out the importance of skill performance for MD activities. Buller (1988) and Argyris (1989) suggested that MD could be part of the corporate strategic planning process. According to them, the strategic planning process should be seen as learning experiences or reflection for problem solving.

While these arguments are useful in illustrating aspects of MD and CA, there is still weakness in the literature in assessing and linking MD and CA. This piece-meal approach to understanding the links has pressured the development of a more integrated approach in connecting the two conceptual dimensions of MD and CA.

\subsection{Method}

The CA models by Hill and Jones (1998) and Smith, Vasudevan and Tanniru (1996) were taken to represent the CA conceptual model (Appendix A). The MD model by Garavan (1997) was taken to represent the MD model.

The methodology used to assess and ascertain the links between MD and CA and organizational performance involves comparing and contrasting these two models through cross referencing. The following steps were employed:

1) The main corresponding criteria in the CA model were identified and matched to each characteristic of the MD model.

2) For each of the three criteria of the CA model, the corresponding number of similar references in the MD model were identified and matched.

\subsection{Results}

Table 1 shows each characteristic of the MD model with the number of corresponding references in the Hill and Jones (1998) and Smith et al.(1996) CA models. The results show that the characteristics of the MD model most frequently referred to in the Hill and Jones (1998) and Smith et al. (1996) model are aligned with vision and strategy, peer learning, improved problem solving, skill building, skill and effectiveness as well as inter and intra personal skills and life skill. Key areas of proactive-related MD described under the MD model such as the manager potential, future role, interaction with the environment (inside out and outside in) and continuous change are not covered to large extent by the Hill and Jones (1998) and Smith et al. (1996) CA models.

Further investigation of the elements in the Hill and Jones (1998) and Smith et al. (1996) CA models criteria are shown in Table 2. The criteria which are referred to the most in the comparison are the more proactive elements of the model. These criteria cover the company skills, people skill, interaction and cooperation, control system as well as cognitive and behavioural development. Organizational structure and tangible assets are the least covered criteria.

In brief, MD provides a mechanism for organizational development which facilitates the creation and sustainability of $\mathrm{CA}$. Hence, it is adequate to indicate that MD has an impact on corporate renewal and success. It is considered to be a means in the process of building CA.

The findings from mutual cross referencing derived from Table 1 and Table 2 above verify that the suggested model to link MD and CA can be established. The conceptual model may add complementary strength to both the effectiveness and efficiency dimensions of organizations.

Figure 2 shows a suggested model of applying MD and CA concurrently towards organizational transformation and performance. Thus, it is adequate to indicate that MD has many common criteria with $\mathrm{CA}$ in terms of organizational success and performance. MD is considered to be a strategic mechanism, a catalytic reinforcer and an effective and efficient system in the process of building organizational competitiveness (Mann, 1990; McClelland, 1994; Millett \& Leppanen, 1991)

\section{Conclusion}

This study indicates that although the underlying definitions of MD and CA are different there have been some 
aspects of convergence or complementary similarity which support commonalities between the two concepts.

The findings of this study are the result of an attempt to compare and contrast the MD and CA models to identify the mutual corresponding criteria. Overall, there seems to be adequate indication to suggest that the MD model corresponds to a large extent with the CA model and that both share common theoretical understanding which concentrates on organizational knowledge and expertise, vision and strategy, learning as well as skill development. Based on the finding in general, it is observed that although the MD and CA models represent individual aspects of study, to a large degree, they are complementary in many similar dimensions particularly on aspects of organizational knowledge and expertise, vision and strategy, learning and skill development.

As a result, in order to strengthen the needs and convince the organizational emancipation of effective participation and practicing of $\mathrm{MD}$, the synergistic and holistic understanding of $\mathrm{MD}$ and $\mathrm{CA}$ can provide a better guideline and methodological framework which serve as overall directive and reference to implement MD initiatives within organizations.

The conceptual framework is recommended to serve as a methodological technique to guide overall business processes to better improvement and help companies become performing organizations especially in terms of implementing and practicing MD.

\section{References}

Argyris, C. 1989. 'Strategic implementation: An experience in learning', Organizational Dynamics, Autumn, pp.5-15.

Arthur, W.B. 1996. 'Increasing returns and the new world of business', Harvard Business Review, vol.74, no.4, pp.100-109.

Asean Economic Bulletin. 1991. vol.8, no.1, pp.104-106.

Atkinson and Meagher. N. 1986. 'Changing patterns of work:How companies introduce flexibility to meet changing needs', Institute of Manpower Studies, London.

Badaracco, J.L. 1991. The Knowledge Link, Havard Business School Press. Boston, MA.

Barney, J.B. 1991. 'Firm Resources and Sustained Competitive Advantage', Journal of Management, vol.17, pp.99-120.

Beddowes, P.L. 1994. 'Management Development', Journal of Management Development, vol.13, no.7, pp.40-47.

Berry, J. 1990. 'Linking Management Development to Business Strategies', Training and Development Journal, vol.44, no.8, pp.20-2.

Boyatzis, R. 1982. The competent manager: A model for effective performance, Wiley, New York, NY.

Buller, P.F. 1988. 'For successful strategic change: Blend OD practices with strategic management', Organizational Dynamics, Winter, pp.42-55.

Burgoyne, J. 1988. 'Management development for the individual and the organization', Personnel Review, vol.20, June, pp.20-24.

Castanias, R.P. and Helfat, C.E. 1991. 'Managerial resources and rents', Journal of Management, vol.17, no.1, pp.155-71.

Catalanello, R. and Redding, J. 1989. 'Three strategic training roles', Training and Development Journal, vol.73, no.12, pp.51-54.

Constable, L. and McCormick, T. 1987. The Making of British Managers, BIM, London.

Day, G.S. and Wensley, R. 1988. 'Assessing advantage: a framework for diagnosing competitive superiority', Journal of Marketing, vol.52, pp.1-20.

Dierickx, I. and Cool, K. 1989. 'Asset stock accumulation and sustainability of competitive advantage', Management Science, vol.35, no.12, pp.1504-11.

Dikken, L. and Hoeksema, L. 2001. 'The palette of management development', Journal of Management Development, vol.20, no.2, pp.168-179.

Doyle, M. 1994. 'Organizational transformation and renewal: A case for reframing management development', Personnel Review, vol.24, no.6, pp.6-18.

Easterby, S.M. 1994. Evaluation of Management training, education and development, Gower, Aldershot.

Foss, N. 1996. 'Research in strategy, economics, and Michael Porter', Journal of Management Studies, vol.3, no.1, pp.1-24.

Garavan, T.N. 1997. 'Training, development, education and learning: different or the same?', Journal of European Industrial Training, vol.21, no.2, pp.39-50. 
Garavan, T.N., Costine, P. and Heraty, N. 1995. Training and Development in Ireland, Context, Policy and Practice, Oak Tree Press, Dublin.

Godfrey, P.C. and Hill, C.W.L. 1995. 'The problem of unobservable in strategic management research', Strategic Management Journal, vol.16, no.7, pp.519-533.

Hamel, G. and Prahalad, C.K. 1994. Competiting for the future: Breakthrough strategies for seizing control of your industry and creating the markets of tomorrow, Havard Business Press, Boston, MA.

Hill, C.W.L. and Jones, G. R. 1998. Strategic Management: An Introduction, Houshton Miffun Co., New York.

Hitt, W. 1987. 'A unified development programme', Journal of Management Development, vol.6, no.1, pp.43-53.

Jansen, P., van der Velve, M. and Mul, W. 2001. 'A typology of management development', Journal of Management Development, vol.20, no.2, pp.106-120.

Jones, J. E. and Woodcock, M. 1985. Manuals for MD, Strategy Design and Instruments for Programme Improvement, Gower, Aldershot.

King, A. W. and Zeithaml, C.P. 2001. 'Competencies and firm performance: Examining the causal ambiguity paradox', Strategic Management Journal, vol.22, pp.75-99.

Lees, S. 1992. 'Ten faces of management development', Journal of Management Development, vol.23, no.2, pp.89-105.

Lippman, S.A. and Rumelt, R.P. 1982. 'Uncertain imitability: An analysis of interfirm differences in efficiency under competition', The Bell Journal of Economics, vol.13, pp.413-38.

Luoma, M. 2000. 'Investigating the link between strategy and HRD', Personnel Review, vol.29, no.6, pp.769-790.

Mabey, C. and Salaman, G. 1995. Strategic Human Resource Management, Blackwell, Oxford.

Mann, R. 1990. 'A Building Blocks Approach to Strategic Change', Training and Development Journal, vol.44, no.8, pp.23-5.

McCall, M. 1992. 'Executive Development as a Business Strategy', Journal of Business Strategy, vol.13, no.1, pp.25-31.

McClelland, S. 1994. 'Gaining competitive advantages through strategic management development', Journal of Management Development, vol.13, no.5, pp.4-13.

Millett, S. and Leppanen, R. 1991. 'The Business Information and Analysis Function: A New Approach to Strategic Thinking and Planning', Planning Review, vol.19, no.3, pp.10-15.

Morgan, G. 1986. Images of organizations, Sage, London.

Mosakowski, E. 1997. 'Strategy making under causal ambiguity: Conceptual issues and empirical evidence', Organization Science, vol.8, pp.414-442.

Mumford, A. 1993. Management Development: Strategies for Action, IPD, London.

Peteraf, M.A. 1993. 'The cornerstones of competitive advantage: A resource-based view, Strategic Management Journal, vol.14, no. 3, pp. 179-91.

Paauwe, J. and Williams, R. 2001. 'Management Development Revisited',Journal of Management Development, vol.20, no.2, pp.180-191.

Pettegrew, A., Henry, C. and Sparrow, P. 1988. 'The role of vocational education and training in employers' skills supply strategies', Sheffield Training Agency report in conjuction with Coopers and Lybrand.

Polanyi, M. 1967. The Tacit Dimension, Anchor, Garden City, NY.

Porter, M.E. 1985. Competitive Advantage: Creating and sustaining superior performance, The Free Press, New York.

Quinn, R.E. 1988. Beyond Rational Management, Jossey-Bass, San Francisco, CA.

Reed, R. and DeFillippi, R. 1990. 'Causal ambiguity, barriers to imitation, and sustainable competitive advantage', Academy of Management Review, vol.15, no.1, pp.88-102.

Rumelt, R. P. 1984. 'Toward a strategic theory of the firm', in Lamb, R.(Ed.), Competitive Strategic Management, Prentice-Hall, Englewood Cliffs, NJ, pp.556-570.

Schuler, R. 1989. 'Strategic Human Resource Management and Industrial Relations', Human Relations, vol.42, no.2, pp.157-84.

Sisson, K. and Storey, J. 1993. Managing human resources and industrial relations, Open University Press, Milton Keynes. 
Smith, K. A., Vasudevan, S.P. and Tanniru, M.R. 1996. 'Organizational learning and resource based theory: An integrative model', Journal of Organizational Change, vol.9, no.6, pp.41-53.

Storey, J. 1989a. 'Management development: A literature review and implications for future research', Personnel Review, vol.18, no.6, pp.3-19.

Storey, J. 1989b. 'Management development: A literature review and implications for future research- part 2', Personnel Review, vol.19, no.1, pp.3-11.

Taylor, B. and Gordon, L. 1984. Management Development and Training Handbook, McGraw-Hill, New York, pp, 31-32.

Teece, D. Pisano, G. and Shuen, A. 1997. 'Dynamic capabilities and strategic management', Strategic Management Journal, vol.18, no.7, pp.509-533.

Torraco, R.J. and Swanson, R.A. 1995. 'The strategic roles of human resource development', Human Resource Planning, vol.18, no.4, pp.10-21.

Torrington, D. and Hall, L. 1998. Human Resource Management, $4^{\text {th }}$ ed., Prentice Hall, London.

Table 1. Cross referencing of MD to CA

\begin{tabular}{|c|c|}
\hline $\begin{array}{l}\text { Management development model } \\
\text { characteristics }\end{array}$ & $\begin{array}{l}\text { Number of corresponding competitive advantage } \\
\text { model references }\end{array}$ \\
\hline 1. Align with vision \& strategy & $9($ mainly criterion part $1 b, 2 a$ and $3 a)$ \\
\hline 2. Peer learning & $8($ mainly criterion part $1 \mathrm{a}, 2 \mathrm{~b}$ and $3 \mathrm{e})$ \\
\hline 3. Improved problem solving & 7 (mainly criterion part $1 \mathrm{c}, 2 \mathrm{~b}$ and $3 \mathrm{~d})$ \\
\hline 4. Skills building & 7 (mainly criterion part $2 a, 2 b$ and $3 a$ ) 7 (mainly \\
\hline 5. Skills \& effectiveness & criterion $2 \mathrm{a}, 2 \mathrm{~b}$ and $3 \mathrm{~d}$ ) \\
\hline 6. Interpersonal skills & 7 (mainly criterion part $2 \mathrm{a}$ and $3 \mathrm{a}$ ) \\
\hline 7. Intrapersonal skills & $6(3 e)$ \\
\hline 8. Life skills & $6(3 c)$ \\
\hline 9. Decision making & $6(3 a)$ \\
\hline 10. Personal competence & $5(3 b)$ \\
\hline 11. Continuous change & $5(3 c)$ \\
\hline 12. Inductive strategy & $2(3 b)$ \\
\hline 13. Outside in & $2(3 b)$ \\
\hline 14. Inside out & $1(3 b)$ \\
\hline 15. Manager potential & $1(3 b)$ \\
\hline 16. Maximising potential & 0 \\
\hline 17. Future role & 0 \\
\hline
\end{tabular}


Table 2. Cross referencing of CA to MD

\begin{tabular}{|l|l|}
\hline Competitive advantage model criteria & $\begin{array}{l}\text { Number of corresponding references in } \\
\text { management development model }\end{array}$ \\
\hline 1. Distinguish knowledge & 12 \\
2. Distinguish expertise & 11 \\
3. Company skills & 10 \\
4. Interaction and cooperation & 7 \\
5. People skills & 6 \\
6. Control system & 6 \\
7. Cognitive development & 3 \\
8. Behavioural development & 2 \\
9. Decision making & 2 \\
10. Organizational structure & 0 \\
11. Tangible assets & 0 \\
\hline
\end{tabular}

\section{Model comparisons:}

CA Model MD Model

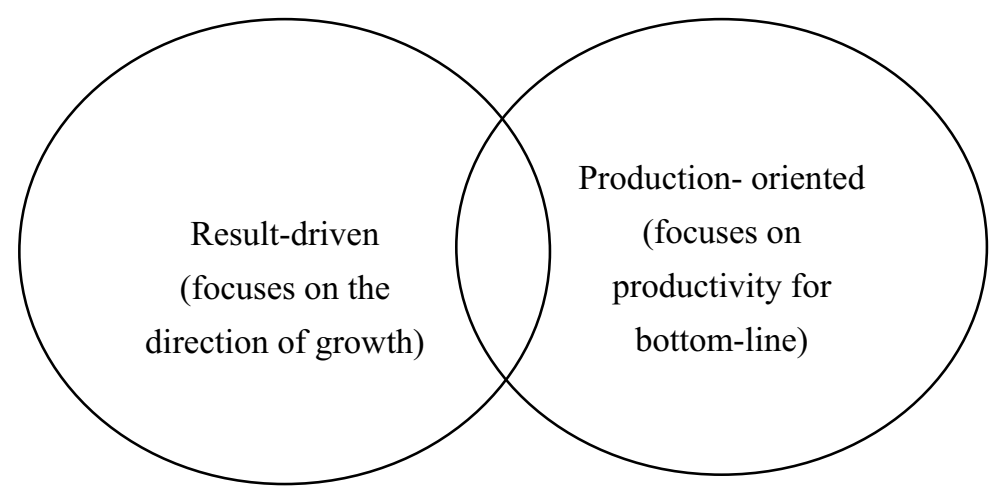

Figure 1. Interaction between management development and competitive advantage

(A proposed conceptual framework)

Figure 1 depicts the suggested model that shows the interaction between CA and MD. Both are not mutually exclusive, rather, they are mutually inclusive in certain aspects. Interaction thus can be expressed through commonality of result-driven and production-driven criteria for effectiveness and efficiency. Therefore, in order to test the suggested model, existing CA and MD models were compared and contrasted

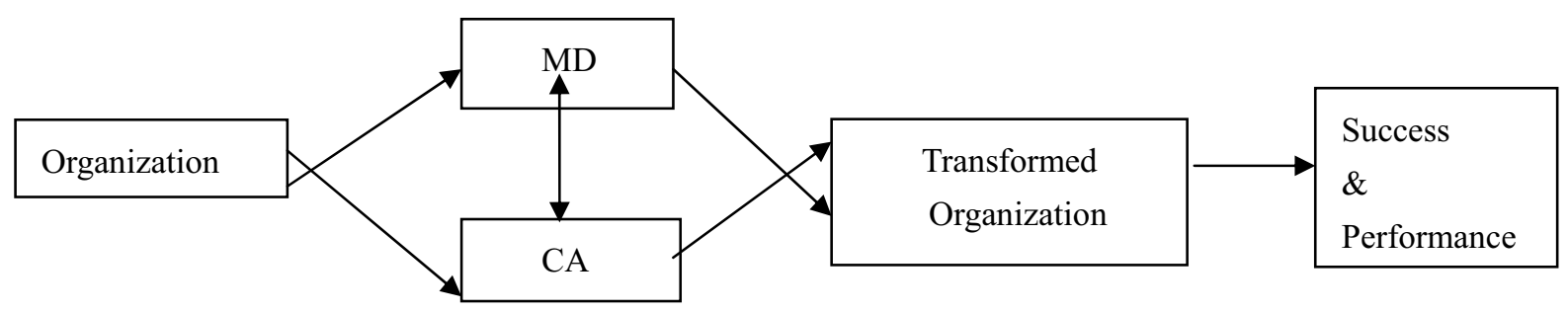

Figure 2. Applying MD and CA methods concurrently to organizational transformation 